
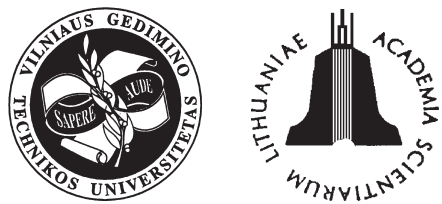

ISSN 1648-4142 TRANSPORT

www.transport.vtu.lt

\title{
TRACTOR BALLASTING IN FIELD TRANSPORT WORK
}

\author{
Kazimieras Giedra ${ }^{1}$, Algirdas Janulevičius ${ }^{2}$ \\ Dept of Transport and Power Machinery, Lithuanian University of Agriculture, Studentu g. 15, \\ Akademija, LT-4324 Kaunas Region, Lithuania. Tel (37) 752285
}

Received 2005-02-10; accepted 2005-05-25

\begin{abstract}
The article presents the investigation of the interaction of tractor traction force, mass, trailer and tractor mass ratio and wheel slippage. The analysis of the influence of ballast weight and wheel slippage on the fuel consumption under various field and road conditions was carried out. Wheel slippage dependence on the pull force, a weight force utilization coefficient and ratio of the mass of a trailer and tractor were stated and analyzed.

The nomogram for operative selection of the optimal ballast weight and its location place is presented when instantaneous wheel slippage is known. The nomogram consists of three parts. In the lower part dependence $\delta=$ $f\left(m_{p} / m\right)$, (wheel slippage on the ratio of the mass of a trailer and tractor) is placed. In the middle part there is dependence of the tractor mass $m$ made of the expression of the wheel grip weight force utilization coefficient $\varphi_{\mathrm{g}}$ $=\mathrm{F}_{\mathrm{t}} / \mathrm{G}$ on the ratio of the mass of a trailer and tractor $m=f\left(m_{p} / m\right)$. The upper part is designed for dependence $\Delta m_{p}=f\left(m_{p}\right)$ (transferred mass of tractor $\mathrm{Dm}_{\mathrm{p}}$ on the rear wheels on the mass trailer $m_{p}$. The bottom part of the nomogram is connected with the middle part by the common abscissa axle on which the ratio of the mass of a trailer and tractor is placed. The curves of the middle part of the nomogram $m=f\left(m_{p} / m\right)$ are connected with the analogical concrete mass trailer values $\mathrm{m}_{\mathrm{p}}$, placed in the abscissa axle by intermediate lines.
\end{abstract}

Keywords: tractor, trailer, ratio of the mass of a trailer and tractor, pull force, ballast weight, wheel slippage, nomogram.

\section{Introduction}

Operation speed $v$ is one of the main exploitation rates of a tractor transport aggregate. Ground speed $v$ depends on variable data: angular velocity of engine $\omega_{e}$, wheel slippage $\delta$, roll radius of driving wheels $r_{v}$, transmission gear ratio $i_{t r}$ :

$$
v=\omega_{e} r_{v}(1-\delta) / i_{t r} .
$$

To count operation speed of the tractor and to set up its alternation character it is necessary to know wheel slippage $\delta$. Wheel slippage $\delta$ depends on traction force $F_{t}$, the conditions of driving wheels and the soil itself [1-3]. Because wheel slippage $\delta$ depends on many factors it is impossible beforehand to count it precisely. The dependence of the wheel slippage on the traction force in correspondent soil is determined according to analogous tractor test data. However, there is no absolute expectation that comparable tractors will characterize completely the same data and that their driving wheels will be loaded by the same forces.

\footnotetext{
${ }^{1}$ E-mail: giedra@info.lzuu.lt

${ }^{2}$ E -mail: jalgirdas@tech.lzuu.lt
}

These loads just determine the driving wheel adhesion with soil and their slippage $[2,4,5,6]$.

Therefore to compare different tractors comparative rates must be used. Such rate is a wheel adhesion weight utilization coefficient $\varphi_{g}$. This coefficient is expressed by the ratio of the traction force $\left(F_{t}\right)$ and the vertical load on the driving wheels $\left(Q_{v}\right)$ : $\varphi_{g}=F_{t} / Q_{v}$.

The vertical load of driving wheels is counted so:

$$
Q_{v}=\lambda G \text {. }
$$

In the case of all driving wheels (4WD) the coefficient of mass distribution between front and rear wheels of a tractor is $\lambda=1$. In tractors with only a rear driving axle $1 / 3$ of the total mass of the tractor must be put on the front wheels $[1,7,8]$. Many companies produce $4 \mathrm{WD}$ tractors so $35-40 \%$ of the total weight of a tractor falls on the front axle $[8,9]$.

Traction features of a tractor depend on dynamic rates of the engine and transmission parameters. Traction features of a tractor depend greatly on driving wheel exploitation characteristics, on the physical-mechanical properties of soil and on the interac- 
tion of driving wheels and soil $[3,10,11]$. The same features have influence on the traction resistance of a trailer. For the purpose to calculate the traction resistance of a trailer its mass $m_{p}$ and the coefficient of the roll $f$ must be known. It depends on the wheel and the soil features on which a tractor is working and the tractor speed.

It was estimated by the tests $[4,7,11]$ that if the tractor is loaded with the traction force, the driving wheels certainly slip on soil. To reduce the slippage of the driving wheels when the tractor is working with the great traction force on soil, the driving wheels must have a correspondent vertical load. It can be achieved selecting suitable ballast weights and mounting them at the suitable place $[4,9]$. The weight of the ballast depends on:

- Road (soil) conditions,

- Type of a trailer,

- Driving speed,

- Traction force,

- Tire type and dimensions,

- Air pressure in tires.

In the case of insufficient ballasting one can expect:

- Driving unevenness,

- Increased wheel slippery,

- Increased power losses,

- Increased wear of tires,

- Increased fuel consumption,

- Reduction of productivity.

Under new ballast (mass) of the tractor the maximal traction force of the tractor changes. Under changing conditions of the soil the wheel grip with the soil and herewith the wheel slippage change. Therefore, evaluating working conditions at the time of exploitation, the quantity of the tractor ballast weights and their mounting area must constantly be changed.

The purpose of the work and the object of investigation are: to set the interconnection between the ratio of the weight of a tractor and trailer, the slippage of the driving wheels and the road (soil) conditions, to create the methodics of choosing the amount of ballast weight and the place of its location.

\section{The analysis of literature and theoretical investi- gations.}

It was estimated, by the reference to the tests [4, $5,7,11]$ that on soil if tractor wheels transmit a driving force, they certainly slip. The dependence of slippage on the traction force on the stubble of tractors John Deere 6800 and Massey Ferguson 6180 with approximately same dynamic characteristics is shown in Fig 1.

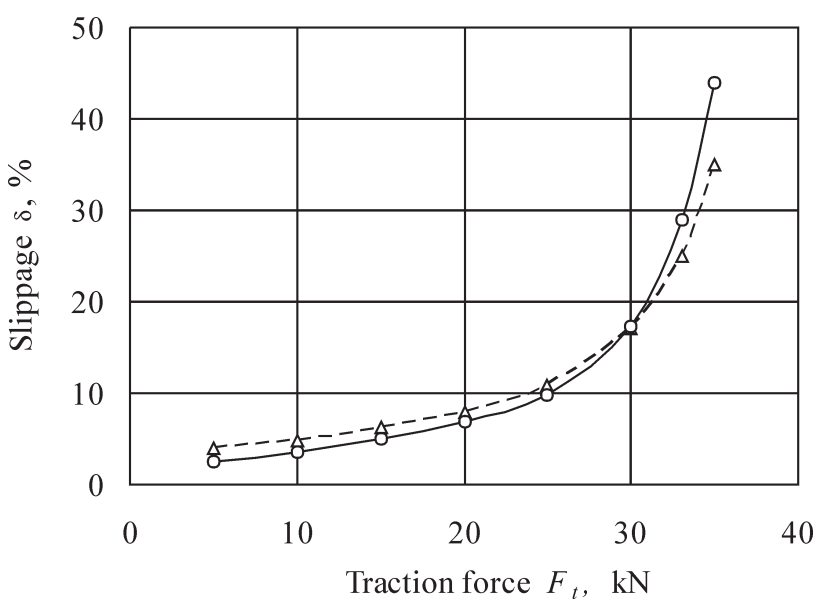

Fig 1. Dependence of wheel slippage on the traction force of tractors John Deere $6800(\Delta)$ and Massey Ferguson $6180(\mathrm{o})$

As it is seen from testing materials of tractors John Deere 6800 and Massey Ferguson 6180 on the loam stubble, the slippage of both tractors increases increasing the traction force in accordance with straight dependence, till the slippage of the wheels reaches $10 \%$. After that, increasing a traction force the slippage increases more intensively to $\delta \mathrm{H}^{\prime \prime} 18$ $20 \%$. Further, only at slight increase of the traction force the slippage increases particularly intensively.

Dependence $\delta=f\left(F_{t}\right)$ (was got with reference to tests of tractors Belarus MTZ-82 (Беларусь MTZ 82 ) (mass $3780 \mathrm{~kg}$ ), John Deere 6800 (mass $6580 \mathrm{~kg}$ ), T-150K (mass $7995 \mathrm{~kg}$ ) and Kirovec K-701 (Кировец К 701) (mass 13690 kg) [4, 7, 11].

As it is shown in Fig 2, the slippage dependence on the traction force of various weight tractors on the uniform soil is different. Driving wheel grip with soil and its slippage determine vertical loads $(G)$ on the driving wheels. In Fig 3 presented dependence $\delta$

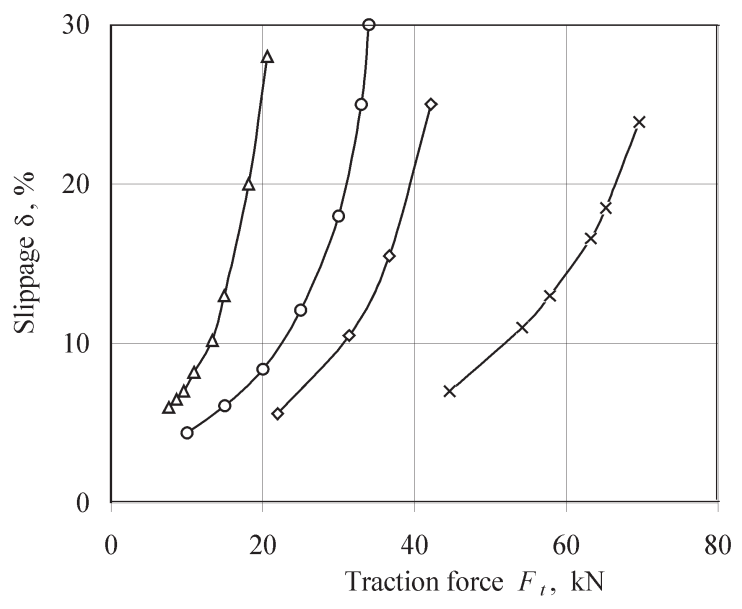

Fig 2. Dependence of wheel slippage on the traction force of tractors Belarus MTZ - $82(\Delta)$ John Deere $6800(\mathrm{o}), \mathrm{T}-150 \mathrm{~K}(\diamond)$ and Kirovec K - $701(\times)$ 
$=f\left(F_{t}\right)$ of tractors Belarus MTZ-82, John Deere $6800, \mathrm{~T}-150 \mathrm{~K}$ and Kirovec K-701 is recalculated into dependence

$$
\delta=f\left(F_{t} / G\right)=f\left(\varphi_{g}\right),
$$

here $\varphi_{g}$ - a weight utilization coefficient.

As it is shown in Fig 3 slippage $\delta$ dependence on the weight utilization coefficient $\varphi_{g}$ on the loam stubble of four different mass tractors changes approximately according to one curve. The greatest difference is between dependence $\delta=f\left(F_{t} / G\right)$ of tractors Belarus MTZ-82 and Kirovec K-701, because these tractors were tested under different soil conditions [7]. Tractor Belarus MTZ-80 was tested on the stubble the humidity of which in $5 \mathrm{~cm}$ depth was $21,6 \%$, hardness $-1,07 \mathrm{MPa}$, humidity in the debth of $10 \mathrm{~cm}-21,4 \%$, and hardness $-1,08 \mathrm{MPa}$, humidity in the debth of $15 \mathrm{~cm}-21,1 \%$, and hardness $-1,09 \mathrm{MPa}$. Tractor Kirovec K-701 was tested on the stubble the humidity of which in $5 \mathrm{~cm}$ depth was $9,5 \%$, hardness - 0,77 MPa, humidity in the depth of $10 \mathrm{~cm}-15,2 \%$, and hardness $-3,03 \mathrm{MPa}$, humidity in the depth of $15 \mathrm{~cm}-14,1 \%$, and hardness 3,58 $\mathrm{MPa}$.

With reference to the test results of tractors Belarus MTZ-82 and John Deere 6800 [4, 7, 8] the dependence of slippage $\delta$ on the weight coefficient $\varphi_{g}$ under various working conditions (Fig 4) was obtained.

Under great ( $>18 \%)$ slippage the structure of soil deteriorates and fuel consumption increases [2, $9,10]$. Therefore wheeled tractors are forbidden to work on soil when the wheel slippage excedes $18 \%$. The fuel consumption for wheel slippage is calculated so:

$$
B_{d \delta}=P_{e} \delta \eta_{t r} b_{e}, 1 / \mathrm{h}
$$

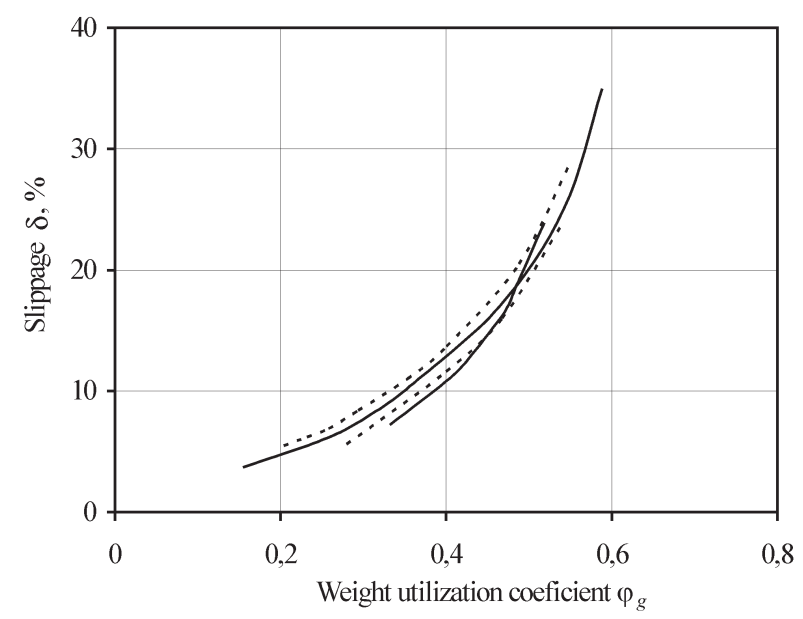

Fig 3. Dependence of wheel slippage on the weight utilisation coefficient of tractors Belarus MTZ-

82, John Deer 6 800, T-150 K and Kirovec K-701

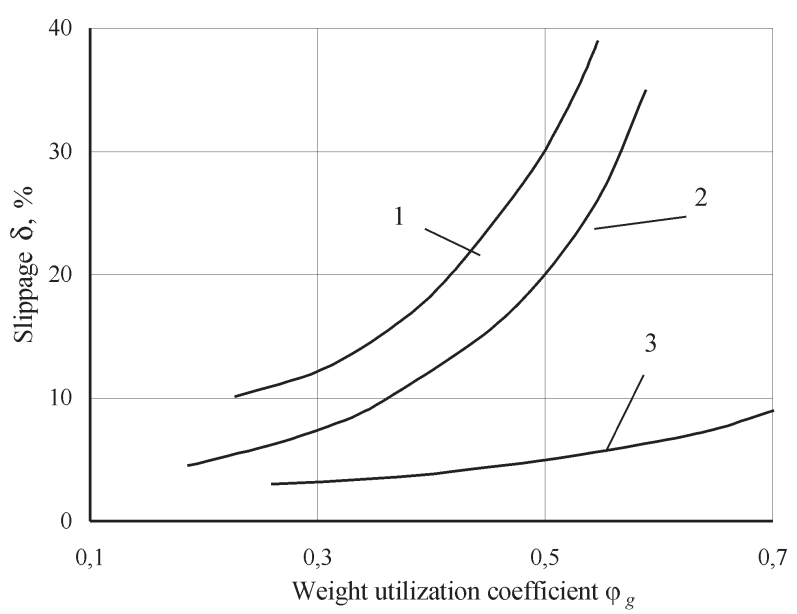

Fig 4. Dependence of wheel slippage on the weight utilisation coefficient of tractors: 1 - on field prepared for sawing; 2 - on stubble; 3 - on asphalt road

here $P_{e}$ - applied engine power, $\delta$ - slippage coefficient, $\eta_{t r}$ - coefficient of transmission efficiency, $b_{e}-$ specific fuel consumption.

When wheel slippage occurs, it increases energy consumption (Fig 5) and decreases productivity. The crop yield on the wheel rut is less, particularly when the rut was done on wet soil $[9,10]$.

Wheel slippage can be reduced reducing the traction resistance, so that the grip force of tractor driving wheels with soil will be major than the resistance force of the trailer. In this occasion the productivity of the work would be reduced, the number of wheeling would be increased and as an outcome fuel consumption would be increased.

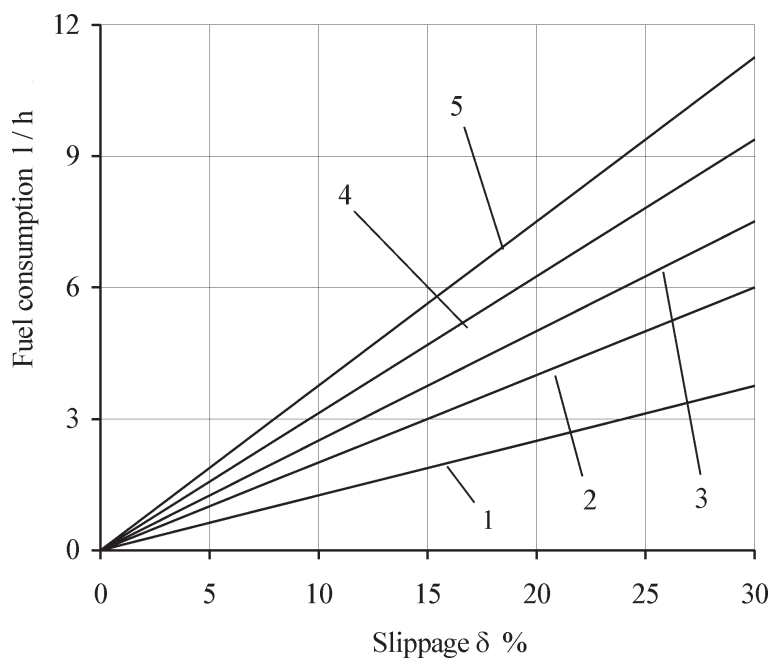

Fig 5. Dependence of fuel consumption on the wheel slippage, when $\eta_{\mathrm{tr}}=0,91, b_{e}=220 \mathrm{~g} / \mathrm{kW} \mathrm{h} \mathrm{:} 1-P_{e}=$ $100 \mathrm{HP}, 2-P_{e}=160 \mathrm{HP}, 3-P_{e}=200 \mathrm{HP}, 4-P_{e}=250$ $\mathrm{HP}, 5-P_{e}=300 \mathrm{HP}$ 
Another variant is to increase the grip force of tractor wheels. This can be carried out improving the wheel grip with soil increasing force pressing the wheels to soil, i.e. increasing the weight on the tractor driving wheels. The wheel grip force depends on the height of the protector and the air pressure in the tires [2, 3]. It is set by investigations set, that the wear of the tire protector $85-90 \%$ and great traction force increase the slippage of driving wheels $8-19 \%$. When the tires are correct, the wheel slippage can be reduced $2-4 \%$ changing the air pressure $[2,10]$. But driving with the low tire pressure on hard surfaces increases roll resistance of the tractor. Therefore the conditions to reduce wheel slippage improving grip with soil are limited. Another way to achieve this aim is more press the tires to soil attaching additional (ballast) weights on that end of the tractor.

With reference to the test results [7] the wheel slippage dependence on the traction force of different weight tractor Belarus MTZ-82 and different road (soil) conditions is presented (Fig 6).

The tests carried out on the stubble the humidity of which in $5 \mathrm{~cm}$ depth was $21,6 \%$, hardness $-1,07$ $\mathrm{MPa}$, the humidity in the depth of $10 \mathrm{~cm}$ was $21,4 \%$, and hardness $-1,08 \mathrm{MPa}$, the humidity in the depth of $15 \mathrm{~cm}$ was $21,1 \%$, and hardness $-1,09 \mathrm{MPa}$ and in the field prepared for sowing, the humidity of which in $5 \mathrm{~cm}$ depth was $20,6 \%$, hardness $-0,25 \mathrm{MPa}$, the humidity in the depth of $10 \mathrm{~cm}$ was $19,8 \%$, and hardness - 0,34 MPa, the humidity in the depth of 15 cm was $19,5 \%$, and hardness - 0,41 MPa.

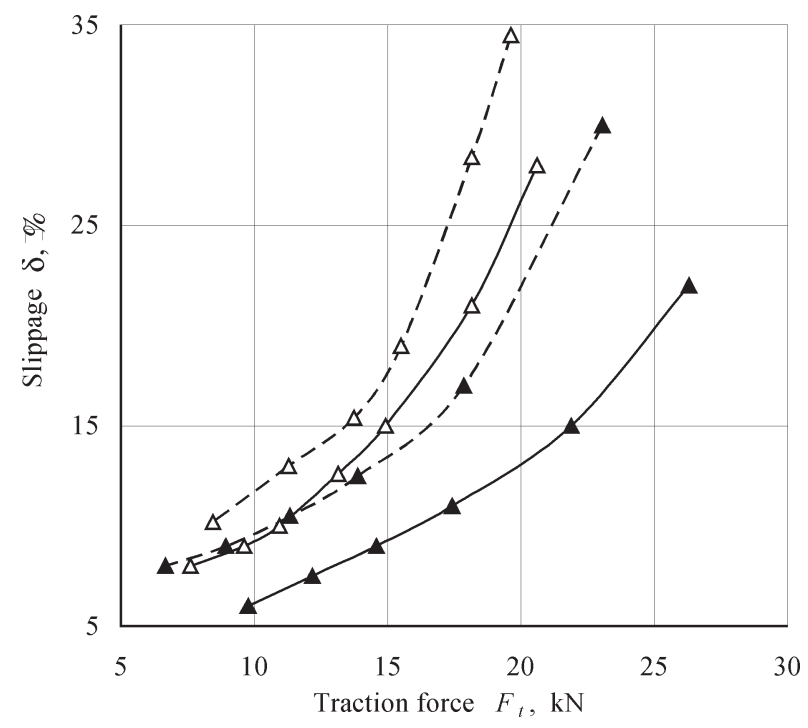

Fig 6. Dependence of wheel slippage on the traction force of tractors Belarus MTZ - 82: ( - ) on stubble, (---- ) on field prepared for sowing, $\Delta$ - with the mass of a tractor $3780 \mathrm{~kg}$,

$\Delta$ - with the mass of a tractor $4840 \mathrm{~kg}$
As it is seen from dependence $\delta=f\left(F_{t}\right)$ (Fig 6), increasing the mass of tractor Belarus MTZ-82 (by ballasting) $60 \mathrm{~kg}$, obviously decreases wheel slippage much on the stubble or on the soil prepared for sowing. For example, when traction force $\left(F_{t}\right) 18 \mathrm{kN}$, increasing the mass of the tractor (by ballasting) $60 \mathrm{~kg}$ the wheel slippage $(\delta)$ decreases: by $9 \%$ on the stubble and $11 \%$ on the soil prepared for sowing.

The ballast weight of the tractor in the period of exploitation is often inconvertible. The same ballast weight is used for difficult and for light transport work. For carrying of ballast weight a lot of fuel is used (Fig 7).

The economy of fuel consumption of agricultural aggregates characterizes specific fuel consumption, and at different engine working speed - fuel consumption per hour [12]. The fuel consumption for carrying ballast weight is counted so:

$$
B_{d b}=m g f v b_{e}, 1 / \mathrm{h},
$$

here $m$ - mass of ballast, $g$ - acceleration of frequent fall, $f$ - coefficient of roll resistance, $v$ - driving speed, $b_{e}$ - engine specific fuel consumption.

As it is seen in Fig 7 carrying of one ton of ballast weight in the soil prepared for sowing uptakes about 0,81 fuel per hour. Increasing driving speed from $8 \mathrm{~km} / \mathrm{h}$ to $40 \mathrm{~km} / \mathrm{h}$ carrying of 1 ton of ballast mass on a dirt road fuel consumption increases approximately $0,5 \% 0,6$ 1/h (Fig 8). But in Figs 5 and 7 it is seen that the increased energy loses for carrying a heavier tractor can compensate less slippage of driving wheels.

Guskov V. V., Velev N. N., Atomanov J. E. [1] recommend to count all tractor weight:

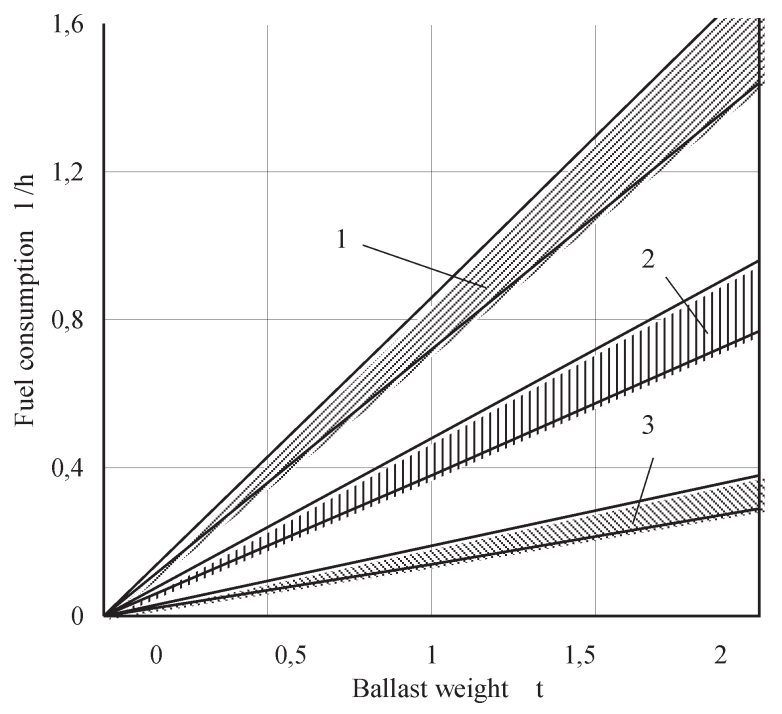

Fig 7. Dependence of fuel consumption on ballast weight, when $v=8 \mathrm{~km} / \mathrm{h}: 1$ - on soil prepared for sowing; 2 - on middle wet stubble, 3 - on a gravel road 


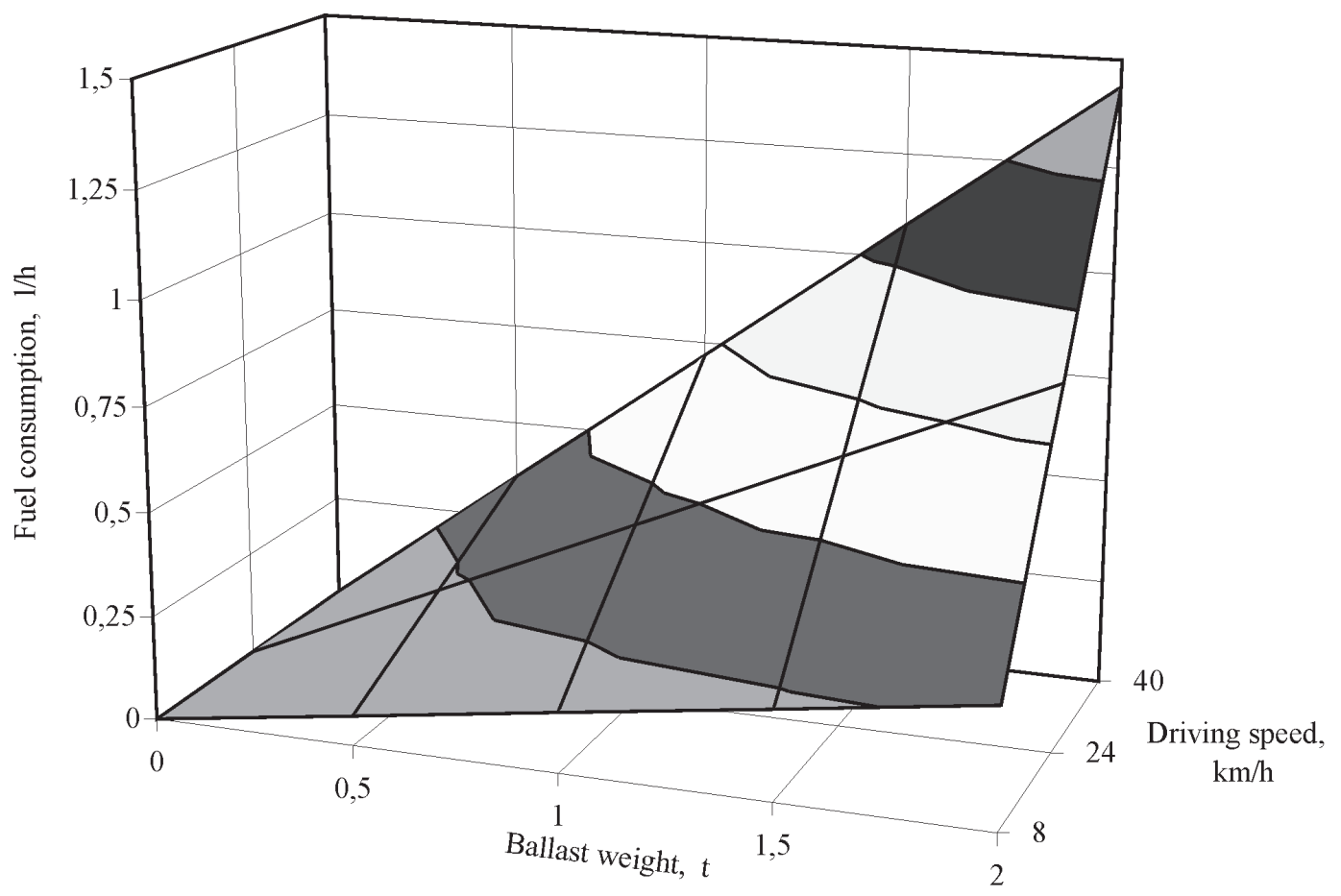

Fig 8. Dependence of fuel consumption on ballast weight and on driving speed on a dry unsurfaced road

$m=(1,35 \div 1,45) F_{t} /[(\lambda \varphi-f) g], \mathrm{kg}$,

here $F_{t}$ - nominal traction force $\mathrm{N}, \lambda$ - mass distribution coefficient between front and rear wheels, $\varphi-$ wheel adhesion with soil coefficient, $f$ - coefficient of roll resistance, $g$ - acceleration of frequent fall $\left(9,81 \mathrm{~m} / \mathrm{s}^{2}\right)$.

In this formula wheel slippage is not shown. Furthermore it is difficult to determine traction force $F_{t}$. When working with the greatest traction force under various field conditions ballast weight often must be changed that wheels of the tractor would less slip [4, 5, 8]. After ballasting (after the change of mass), nominal traction force of tractor $F_{t}$ changes.

Evaluating the engine power tractor mass can be selected according to the equation:

$$
m=\frac{P_{e} \cdot \chi_{p} \cdot \eta_{t r} \cdot 3600}{(\lambda \varphi-f) \cdot v g}, \mathrm{~kg},
$$

here $P_{e}$ - engine power $\mathrm{kW}, \chi_{p}$ - engine overload coefficient, $\eta_{t r}-$ coefficient of transmission efficiency, $v$-ground speed $\mathrm{km} / \mathrm{h}$.

Accepting: $\chi_{\mathrm{p}}=1,15 ; \eta_{t r}=0,92 ; \lambda=1,0 ; \varphi=$ 0,$65 ; f=0,05$ we get equation:

$$
m=\frac{647 \cdot P_{e}}{v} .
$$

This equation is analogous to Silsoe Research
Institute (USA) formula to collect the weight of the tractor:

$$
m=\frac{650 \cdot P_{e d v}}{v}, \mathrm{~kg},
$$

here $P_{e}$-engine power measured through PTO kW, $v$ - tractor speed $\mathrm{km} / \mathrm{h}$.

It is seen from formulas (4), (5) and (6) that increasing the driving speed tractor mass can be reduced.

Traction resistance $F_{p}$ of a trailer with mass $m_{p}$ on the road (field) on which coefficient of roll resistance $f$ can be counted so:

$$
F_{p}=m_{p} g(f \cos \alpha \pm \sin \alpha) .
$$

On the flat surface when $\alpha=0$ :

$$
F_{p}=f m_{p} g .
$$

Evaluating the power of tractor engine $P_{e}$, engine overload coefficient $\chi_{p}$, driving speed $v$, coefficient of transmission efficiency $\eta_{t r}$ and road conditions corresponding roll resistance coefficient $f$, the trailer mass is chosen according to the equation:

$$
m_{p}=\frac{P_{e} \cdot \chi_{p} \cdot \eta_{t r} \cdot 3600}{f v g} .
$$

From (5) and (10) equations the formula of the ratio of trailer and tractor mass $m_{p} / m$ can be written: 


$$
m_{p} / m=\frac{\lambda \varphi-f}{f} .
$$

Evaluating the uphill parameter $\alpha$, equation 11 can be rewritten so:

$$
m_{p} / m=\frac{(\lambda \varphi-f) \cos \alpha+\sin \alpha}{f \cos \alpha+\sin \alpha} .
$$

With reference to specification $\varphi_{g}=F_{t} / G=$ $\mathrm{fm}_{p} / \mathrm{m}$ and in Fig 9 presented curves, construct the dependence of tractor slippage $\delta$ on trailer and tractor mass ratio $m_{p} / m$ under various working conditions.

As it is seen in Fig 9, the size of a trailer and tractor mass ratio in field operation can be considerably less than driving on an asphalt road. It is possible to observe that slippage of the tractor wheels reaches $18-20 \%$, when the mass ratio of the trailer and tractor in the field prepared for sowing will be $m_{p} / m \geq 3,4-4,0$ and in the stubble $m_{p} / m \geq 5,0-5,5$. Furthermore, working under field conditions and increasing ratio $m_{p} / m$, the slippage increases very intensively. Therefore, working under various field conditions for less slippage of the tractor wheels it is necessary to correct the selection of ballast weight and this weight must be frequently changed. The correct tractor ballasting considerably improves tractor traction and speed conditions and economy.

Furthermore, when driving on the field, soil is less compressed and soil structure is less spoiled [1, $3,9]$. Applying great ballast weight we:

- increase transmission wear,

- increase power loses,

- increase soil compaction,

- increase fuel consumption,

- decrease work productivity.

The slippage graphic is one of the most important graphics of the traction characteristics because

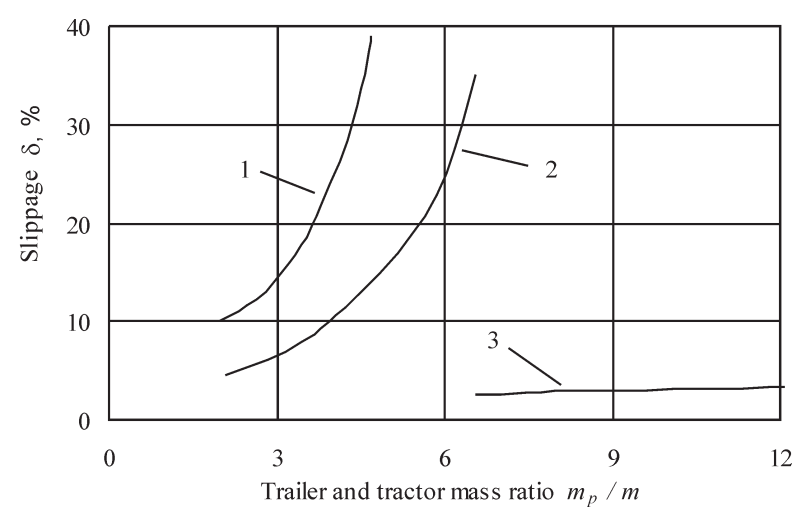

Fig 9. Dependence of wheel slippage on the mass ratio of the trailer and tractor $m_{p} / m: 1-$ on soil prepared for sowing, 2 - on stubble, $3-$ on an asphalt road other tractor parameters (traction power, economics) depend on slippage size.

The USA scientist Frank Zoz [8] suggests transferred weight from the front axle to the rear count according to a simple formula:

$$
\Delta G=\xi F_{t}, \mathrm{~N}
$$

here $\xi$ - coefficient, evaluating transferred weight, $\Delta G$ - transferred weight $\mathrm{N}$.

F. Zoz set [8] that for trailing machines $\xi=0,2$ and for semi mounted machines $\xi=0,45$.

\section{Results of the investigation}

For setting the interaction of a trailer and tractor mass ratio $m_{p} / m$ and the slippage of driving wheels a nomogram was made (Fig 10) consisting of three interdependent parts. In the bottom part dependence of wheel slippage on trailer and tractor mass ratio $\delta=$ $f\left(m_{p} / m\right)$ adequate for stubble, the humidity of which in $5 \mathrm{~cm}$ depth is $21,6 \%$, hardness is $1,07 \mathrm{MPa}$, in 10 $\mathrm{cm}$ depth the humidity is $21,4 \%$, hardness is 1,08 MPa and in $15 \mathrm{~cm}$ depth humidity is $21,1 \%$, hardness is 1,09 MPa and on the soil prepared for sowing in 5 $\mathrm{cm}$ depth the humidity is $20,6 \%$, hardness is $0,25 \mathrm{MPa}$, in $10 \mathrm{~cm}$ depth the humidity is $19,8 \%$, hardness is $0,34 \mathrm{MPa}$ and in $15 \mathrm{~cm}$ depth the humidity is $19,5 \%$, hardness is $0,41 \mathrm{MPa}$ is presented. This dependence was got using experimental data (see Figs 6 and 7). So, using experimental data dependence $m=f\left(m_{p} /\right.$ $m$ ) was designed and located in the middle part of the nomogram. Changing the ratio of mass of trailer and tractor $m_{p} / m$, the mass of the tractor $m$ was calculated at the same mass of the trailer $m_{p}$ and plot the curves $m=f\left(m_{p} / m\right)$ correspondent to $m_{p}=3 ; 6 ; 9$; $12 ; 15 ; 18 ; 21 ; 24 ; 27$ t.

In the top part dependence $\Delta m=f\left(m_{p}\right)$ is placed (dependence of the tractor weight force transferred to the rear wheels $\Delta m$ on the mass of trailer $m_{p}$.

The bottom part of the nomogram is connected with the middle part by a common abscise axle on which the ratio of mass of trailer and tractor $m_{p} / m$ is put.

The curves of dependence of the middle part $m=f\left(m_{p} / m\right)$ made for concrete mass of trailers $m_{p}$ connected with the analogical trailer mass $m_{p}$ data placed on the top part of the abscise axle are connected by the intermediate lines.

Using the nomogram it is possible to set optimal ballast weight of the tractor and mounting place: on the bottom part of the ordinate axle we place wheel slippage $\delta$ (instantaneous wheel slippage display on the instrument cluster) and the mass of tractor $m-$ on the middle part of the ordinate axle. Draw a horizontal line from the placed point $\delta$ to the right till the slippage curve corresponds working conditions (point 


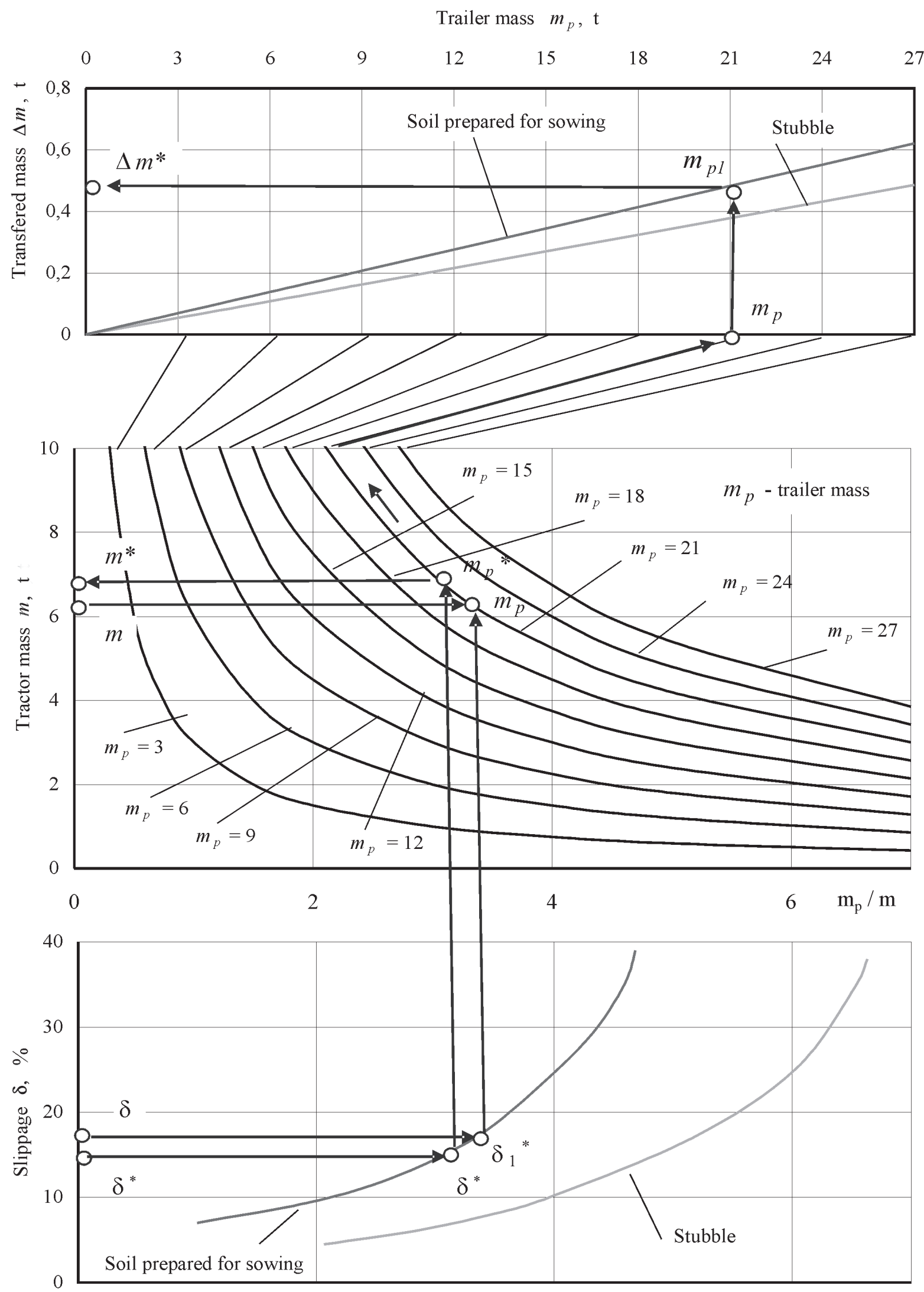

Fig 10. Nomogram for setting slippage and optimal ballast mass and the place of mounting it on the tractor working with a trailer on the soil prepared for sowing and stubble 
$\delta_{1}$ ). Draw a vertical line from point $\delta_{1}$ and from point $m$ placed at the middle part of the ordinate axle a horizontal line to the right to the intersection of these lines (point $m_{p}$ ). Point $m_{p}$ shows trailer mass $m_{p}$.

If point $m_{p}$ is located between the curves, we must draw a proportional intermediary curve. If current slippage is too great, in such case put the desirable value of slippage $\delta^{*}$ on the bottom part of the ordinate axle. Draw a horizontal line from that point $\delta^{*}$ to the right till working conditions correspond slippage curve (point $\delta_{1}{ }^{*}$ ). Draw a vertical line from point $\delta_{1}{ }^{*}$ to curve $m_{p}$ (point $m_{p}{ }^{*}$; because $m_{p}{ }^{*}$ and $m_{p}$ are on the same curve so $m_{p}{ }^{*}=m_{p}$ ). Draw a horizontal line from point $m_{p}{ }^{*}$ to ordinate axle of the middle part. Here we get the required mass of tractor $m^{*}$ to maintain the required wheel slippage $\delta$. To decrease the wheel slippage from $\delta$ to $\delta^{*}$ additional ballast $\Delta m$ $=m^{*}-m$ is necessary.

Knowing the mass of trailer $m_{p}$ we can get the transferred force of mass $\Delta m^{*}$ on the tractor rear wheels. For this purpose using the curve of trailer mass $m_{p}$ and straight line connecting upper part of nomogram put the trailer mass on abscise axle on top part of the nomogram (point $m_{p}$ ). Draw a vertical line from point $m_{p}$ till the line defines the tractor and trailer connection mode and conditions of the road (point $m_{p 1}$ ). Draw a horizontal line from point $m_{p 1}$ to the ordinate axle of the top part. Here we can know the transferred force of mass $\Delta m$ * on the tractor rear wheels. If it is very big, the ballast weight must be fixed in the front of the tractor dismounting it from the rear wheels. In this case best of all it is to mount the ballast weight on the front three point hitch, as far as possible to the front.

Transferred force of the mass is very great working with the three point hitch and electronic draft control (Figs 3 and 9).

\section{Conclusions}

1. The use of excessive ballast mass is useless particularly when working at high speed or on swampy soils (carrying one ton of the ballast mass on soil prepared for sowing at the speed of $8 \mathrm{~km} / \mathrm{h}$ tractor uses about $0,6 \mathrm{l} / \mathrm{h}$ fuel. So carrying one ton of ballast mass and increasing the driving speed from $8 \mathrm{~km} / \mathrm{h}$ to 40 $\mathrm{km} / \mathrm{h}$ on the subsurface road the fuel consumption increases by $0,6 \mathrm{l} / \mathrm{h}$. However the increased fuel consumption for carrying ballast mass can be compensated by the lower fuel consumption because of the diminished wheel slippage. Therefore for efficient tractor performance under various field conditions it should be properly ballasted.
2. Wheel slippage during tractor field transport operations can be evaluated using a trailer and tractor weight ratio.

3. Knowing road/field conditions and allowable slippage it is possible to set the optimal trailer and tractor mass ratio.

\section{References}

1. Guskov, V. V.; Velev, N. N.; Atomanov, J. E. and etc. Tractors; Theory (Тракторы: теория). Moscow: Mashinostrojenie, 1988. 376 p. (in Russian).

2. Grašys, V.; Janulevičius, A. Mode and means of automatic adjusting of tractor driving wheel lead (Traktoriaus varančiųjų ratų apkrovos automatinio reguliavimo būdai ir priemonès). Kaunas-Akademija, 1999. 32 p. (in Lithuanian).

3. Prentkovskis, O.; Bogdevičius, M. Dynamics of a motor vehicle Taking into Consideration the Interaction of Wheels and Road Pavement Surface. Transport, Vol XVI, No 6. Vilnius: Technika, 2002, p. 244-253.

4. Neunaber, M. Correct ballast boosts draft by $20 \%$ or more. Profi, No 10, 1997, p. 46-49.

5. Zhadik, P.V.; Zhadik, A. B. Automatical corrector of vertical load according to slippage (Автоматический корректор вертикальных нагрузок по буксованию). Tractors and Agricultural Machines (Тракторы и сельскохозяйственные машины), 2004, No 4, p. 24-25 (in Russian).

6. Janulevičius, A.; Giedra, K. The evaluation of braking efficiency of traction transport aggregate. Transport, Vol XVII, No 4. Vilnius: Technika, 2002, p. 152-158.

7. Traction Characteristics of Agricultural Tractors (Тяговые характеристики сельскохозяйственных тракторов). Albume-Manuel (Альбом-справочник). Moscow: Rosselchozizdat, 1979. 240 p. (in Russian).

8. Carrol, E. Gearing Engine and Tractor Power: ASAE Text Book No 7. Michigan, 1992. 539 p.

9. Upadhyaya, S.; Sime, M.; Radhuashi, N.; Adler, B. Semiempirical traction prediction equations based on relevant soil parameters. J. Terramechanics, 1997, 34 (3), p. 141-154.

10. Jun, H.; Kishimoto, T.; Way, T. R.; Tauiguhi, T. Threedirectional contact stress distributions for a pneumatic tractor tire in soft soil. Transactions of the ASAE, Vol 41, No 5, 1998 , p. 1237-1242.

11. Neunaber, A. Scarlett Weight Watching Proves to be Worthwhile. Profi, No 3, 1998, p. 10-14.

12. Kraujalis, A. Analysis of fuel input of driving tractor units. (Pavarinių traktorinių agregatų degalų sąnaudų analizè). Agricultural engineering (Žemès ūkio inžinerija), Vol 34, No 3, Raudondvaris, 2002, p. 35-42. 